\title{
HYPOCHOLESTEROLEMIC EFFECT OF PRAVASTATIN IS ASSOCIATED WITH INCREASED CONTENT OF ANTIOXIDANT VITAMIN-E IN CHOLESTEROL FRACTIONS
}

\author{
Vladimír Bláha, Zdeněk Zadák, Dagmar Solichová, Miluše Brátová, Eduard Havel \\ Department of Metabolic Care and Gerontology, Charles University, Faculty of Medicine and Teaching Hospital, \\ Hradec Králové; (Head: prof. MUDr. Z. Zadák, CSc.)
}

\begin{abstract}
Summary: Metabolic studies support the findings that antioxidants inhibit atherosclerosis. Treatment with vitamin E reduced both the susceptibility of low density lipoprotein cholesterol (LDL-C) to in vivo lipid peroxidation and atherosclerosis and smooth muscle proliferation. Thus the aim of present study was to examine metabolic consequences of reduced plasma LDL-C during hypolipidemic therapy and the distribution of antioxidant vitamin E. A group of 10 patients (4 men, 6 women, age $35-65 y$ ) with familial hypercholesterolaemia was treated using pravastatin (Lipostat ${ }^{\circledR}$ Bristol Myers Squibb, $40 \mathrm{mg}$ daily at $6.00 \mathrm{PM}$ ). Blood samples were examined before treatment, after 4 and 8 weeks of therapy. After ultracentrifugation, samples were analyzed for lipoprotein fractions and the content of vitamin $\mathrm{E}$ and cholesterol. Pravastatin reduced both total cholesterol ( $9.85 \pm 0.74$ vs. $6.81 \pm 0.51 \mathrm{mmol} / \mathrm{l} ; \mathrm{p}<0.01)$, LDL-C (6.42 $\pm 0.45 \mathrm{vs} .4 .51 \pm 0.45 \mathrm{mmol} / \mathrm{l} ; \mathrm{p}<0.01)$, light LDL1-C (4.56 \pm 0.50 vs. $3.11 \pm 0.34 \mathrm{mmol} / \mathrm{l} ; \mathrm{p}<0.05)$ and dense LDL2-C (1.86 \pm 0.27 vs. $1.42 \pm 0.17 \mathrm{mmol} / \mathrm{l}$; ns). Serum vitamin $\mathrm{E}$ was reduced during hypolipidemic therapy in the fraction of total, LDL1, LDL2 and VLDL-cholesterol. However, the ratio of serum vitamin E/total serum cholesterol $(4.57 \pm 0.32 \mathrm{vs}$. $5.12 \pm 0.37 \mathrm{mmol} / 1 / \mathrm{mmol} / 1$; $\mathrm{p}<0.05)$ and ratio of LDL2-C vitamin E/LDL2-C (3.92 \pm 0.07 vs. $4.64 \pm 0.37 \mathrm{mmol} / 1 / \mathrm{mmol} / 1 ; \mathrm{p}=0.08)$ increased in comparison to pre-treatment values. We conclude that pravastatin therapy may possess anti-atherogenic properties which involve not only its hypocholesterolemic effect, but also its favorable effects on the distribution of LDL subclasses and the content of antioxidant vitamin $\mathrm{E}$ in atherogenic lipoproteins.
\end{abstract}

Key words: Antioxidants; Vitamin E; Atherosclerosis; Lipoprotein fractions; Lipid peroxidation

\section{Introduction}

Oxidative modification of low density lipoprotein (LDL) is the key event in the initiation and development of atherosclerosis (21). Macrophages, the precursors of most foam cells in early stages of atherosclerotic lesions, cannot take up native LDL quickly enough to cause lipid loading (19). However, macrophages take up considerable quantities of oxidatively modified LDL, leading to their loading with cholesterol and cholesteryl esters (17). Oxidized LDL possesses additional atherogenic properties, because it is highly toxic to cells and may be responsible for further damage to the endothelial layer and destruction of smooth muscle cells (8).

Circulating LDL particles in plasma are protected from the effects of lipid peroxidation by cellular and extracellular antioxidant mechanisms which serve to trap reactive oxygen species close to their site of formation and which also function to inhibit the chain reaction of free radical formation. LDL-particles contain fat-soluble endogenous antioxidants that can also prevent or limit the chain reaction of lipid peroxyl radical formation. These natural antioxidants, which include ubiquinol, vitamin $\mathrm{E}$, lycopene and $\beta$-carotene, are preferentially oxidized before oxidation of LDL polyunsaturated fatty acids $(7,22)$. Vitamin $\mathrm{E}$ is quantitatively the most abundant endogenous antioxidant present in LDL, and in vitro studies suggest that $\alpha$-tocopherol slows down the oxidation of LDL and prevents the cytotoxic action of this event on the cellular processes (6).

In addition to their LDL-lowering effect, statins may have further beneficial effects on LDL metabolism and LDL composition. Statins increase LDL receptor activity, mainly in the liver, and thus contribute to removal of aged LDL particles from the circulation (20). Studies have shown greater resistance to in vitro oxidation of LDL from subjects treated with statins (13). Such effects may correlate with the concentration of endogenous $\alpha$-tocopherol in isolated LDL.

The aim of present study was to evaluate the effects of pravastatin on the content of endogenous vitamin $\mathrm{E}$ in lipoprotein subfractions and on the distribution of LDL subclasses during such hypolipidemic intervention. 


\section{Material and Methods}

\section{Study design}

This protocol comprises an open, single-center study. Ten patients ( 4 men, 6 women, age $35-65 y$ ) with familial hypercholesterolaemia were treated using pravastatin (Pravastatin ${ }^{\circledR}$, Bristol-Myers-Squibb, 40mg daily with the evening meal). The subjects were not taking vitamin supplements before the study. Approximately $20 \%$ of the subjects were treated by other hypolipidemic drugs before the study, and had stopped such treatment at least 6 weeks before the entry into the study. Upon entry into the 6-week baseline phase and further on, patients were counseled to follow the National Institute of Health (NIH) Cholesterol Education Program (NCEP) Step I diet which limits dietary cholesterol to $<300 \mathrm{mg} /$ day, saturated fats $<10 \%$ of total calories, and total fats to $<30 \%$ of total calories (9).

The baseline biochemical characteristic of the patient group was as follows: total cholesterol (TC) $9.85 \pm 0.74$ $\mathrm{mmol} / 1$, low density cholesterol (LDL-C) 6.42 \pm 0.45 $\mathrm{mmol} / 1$, and triacylglyceroles $2.91 \pm 0.42 \mathrm{mmol} / 1$.

The study protocol had been accepted by local ethical committee, Charles University, Faculty Hospital, Hradec Králové, Czech Republic.

\section{Methods}

Blood samples were examined at the beginning of the study, after 4 and 8 weeks of therapy after twelve hour overnight fasting.

Lipoprotein fractions were detected by density gradient ultracentrifugation (Beckman TL 100, Palo Alto, CA) (18). The lipoprotein fractions were distinguished in the following density ranges: VLDL $<1.006 \mathrm{~g} / \mathrm{ml}$; LDL1 <1.019 $\mathrm{g} / \mathrm{ml}$; LDL2 <1.063 g/ml; HDL >1.063 g/ml. The fractions were analyzed for content of vitamin A, E and C by HPLC (Hewlett Packard 1084 A, Palo Alto, CA) and fluorescence detector (Perkin Elmer MPF-3, Norwalk, CT) (1,5). Total concentration and/or lipoprotein fraction concentration of cholesterol (3) and triacylglyceroles (4) were assessed enzymatically by conventional diagnostic kits (Lachema, Brno, Czech Republic) and spectrophotometric analysis (ULTROSPECT III, Pharmacia LKB Biotechnology, Uppsala, Sweden).

\section{Statistical analysis}

Values are reported as means \pm SEM. Data were analyzed by paired t-test using BMDP software (Solo 4.0, Charles University Medical Faculty, Hradec Králové, Czech Republic). A value of $\mathrm{p}<0.05$ and less was taken as criterion of significance.

\section{Results}

\section{Total cholesterol.}

Pravastatin was an effective hypolipidemic drug, and significantly reduced total plasma cholesterol after 8 weeks of therapy $(9.85 \pm 0.74$ vs. $7.92 \pm 0.68 \mathrm{mmol} / \mathrm{l} ; \mathrm{p}<0.01$; not shown in Figures).

\section{LDL, LDL1, LDL2 and HDL-cholesterol.}

The treatment with pravastatin significnatly reduced plasma LDL-C (6.42 \pm 0.45 vs. $4.51 \pm 0.45 \mathrm{mmol} / \mathrm{l} ; \mathrm{p}<0.01)$, light LDL1-C $(4.56 \pm 0.23$ vs. $3.36 \pm 0.45 \mathrm{mmol} / \mathrm{l} ; \mathrm{p}<0.01)$ and heavy LDL2-C (1.86 \pm 0.50 vs. $1.26 \pm 0.11 \mathrm{mmol} / \mathrm{l}$; $\mathrm{p}<0.05$ ) after 8 weeks of therapy (Figure 1). HDL-C did not change significantly after 8 weeks of therapy $(1.22 \pm 0.15 \mathrm{vs}$. $1.03 \pm 0.08 \mathrm{mmol} / \mathrm{l}$; n.s.; not shown in Figures).

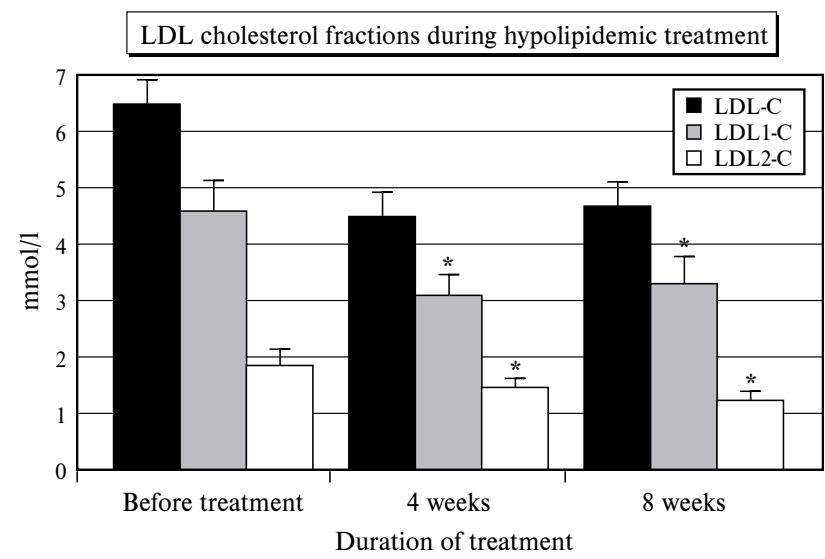

Fig. 1: The changes in serum LDL, LDL1 and LDL2 cholesterol in patients with familial hypercholesterolaemia treated using pravastatin (Bristol-Myers-Squibb, 40mg daily with the evening meal). Blood samples were examined at the beginning of the study, and after 4 and 8 weeks of therapy. The results are reported as means \pm SEM. Statistical significance vs. values before treatment is indicated by asterisk above particular bar.

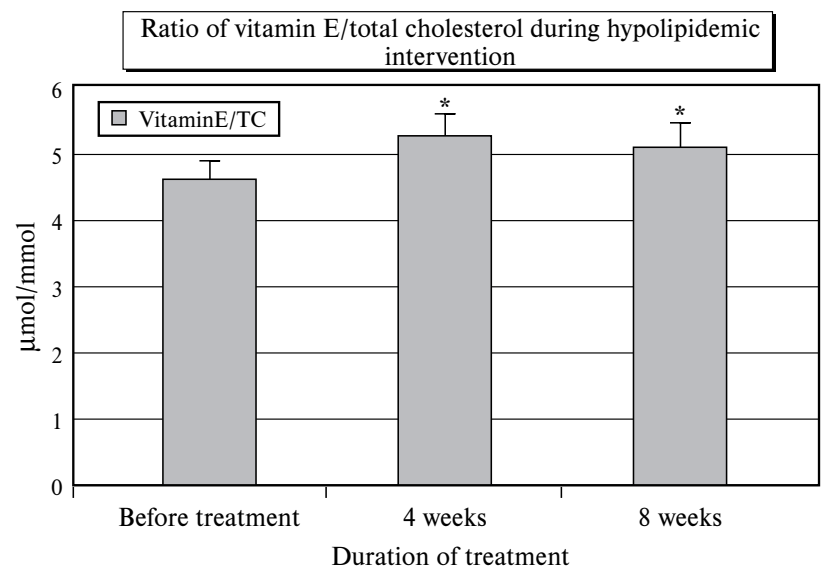

Fig. 2: Ratio of serum vitamin $\mathrm{E}$ in total cholesterol/total cholesterol in patients with familial hypercholesterolaemia treated using pravastatin (Bristol-Myers-Squibb, 40mg daily with the evening meal). Blood samples were examined at the beginning of the study, and after 4 and 8 weeks of therapy. The results are reported as means \pm SEM. Statistical significance vs. values before treatment is indicated by asterisk above particular bar. 
Vitamin $E$ in lipoprotein fractions.

The serum vitamin $\mathrm{E}$ was reduced after 8 weeks of hypolipidemic therapy in the fractions of total cholesterol (44.11 \pm 3.36 vs. $39.51 \pm 3.42 \mu \mathrm{mol} / 1$; n.s.; not shown in Figures), LDL1-cholesterol ( $16.34 \pm 1.86$ vs. $11.29 \pm 01.35$ $\mu \mathrm{mol} / 1$; $\mathrm{p}<0.05$; not shown in Figures), LDL2-cholesterol (7.27 \pm 1.01 vs. $7.04 \pm 1.37 \mu \mathrm{mol} / 1$; n.s.; not shown in Figures), and VLDL-cholesterol (15.79 \pm 2.70 vs. 13.94 $\pm 3.49 \mu \mathrm{mol} / 1$; n.s.; not shown in Figures). However, the ratio of serum vitamin E/total serum cholesterol ( $4.57 \pm 0.32$ vs. $5.12 \pm 0.37 \mu \mathrm{mol} / \mathrm{mmol} ; \mathrm{p}<0.05)$ (Figure 2) and ratio of LDL2-C vitamin E/LDL2-C (3.92 \pm 0.07 vs. $4.64 \pm 0.37 \mu \mathrm{mol} / \mathrm{mmol} ; \mathrm{p}=0.08$ ) (Figure 3 ) increased in comparison to the pre-treatment values after 8 weeks of therapy.

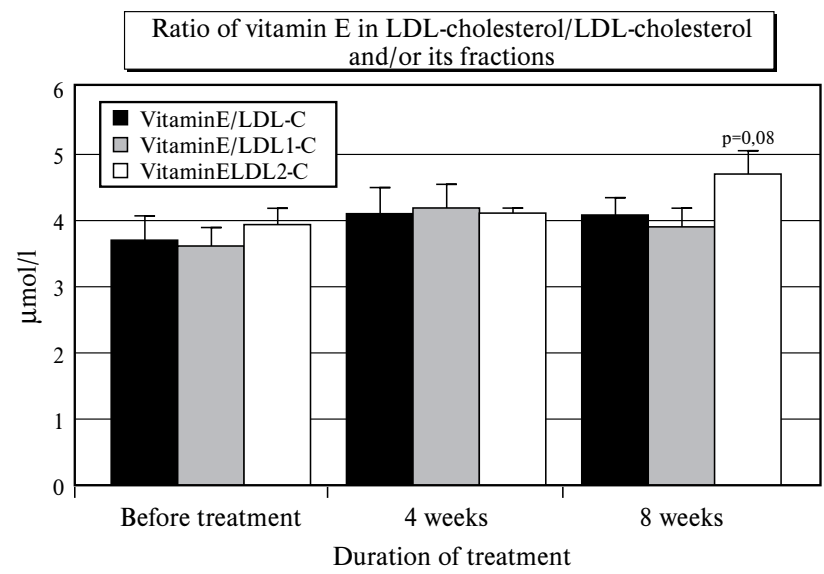

Fig. 3: Ratio of serum vitamin E in LDL, LDL1 and LDL2 cholesterol / LDL, LDL1 and LDL2 cholesterol in patients with familial hypercholesterolaemia treated using pravastatin (Bristol-Myers-Squibb, 40mg daily with the evening meal). Blood samples were examined at the beginning of the study, and after 4 and 8 weeks of therapy. The results are reported as means \pm SEM. Statistical significance vs. values before treatment is indicated above particular bar.

\section{Vitamin A, vitamin $C$.}

The serum content of vitamin A $(1.87 \pm 0.11$ vs. $2.27 \pm 0.17 \mu \mathrm{mol} / 1$; n.s.; not shown in Figures) and vitamin C (48.50 \pm 6.98 vs. $47.35 \pm 8.10 \mu \mathrm{mol} / 1$; n.s.; not shown in Figures) did not change significantly during hypolipidemic therapy.

\section{Discussion}

Intervention that may reduce LDL oxidation is considered to be antiatherogenic. The present study demonstrated that pravastatin therapy, in addition to its hypocholesterolemic effects on plasma LDL, significantly decreased the small, dense LDL2, increased the content of vitamin $\mathrm{E}$ in total cholesterol and non-significantly in dense LDL2-cholesterol fractions. Subjects in this study were not vitamin-E deficient (15) and had concentrations of plasma vitamin E slightly above the range observed by others (16). It is of interest, that the serum vitamin A and vitamin $\mathrm{C}$ did not change significantly during hypolipidemic therapy. We suggest that the substantial increment of vitamin $\mathrm{E}$ in cholesterol and LDL subclasses, despite its total concentration decreased or did not change, may be the result of the hypocholesterolemic effect of pravastatin.

Human LDL contains a variety of antioxidants that can inhibit lipid peroxidation, including $\alpha$-tocopherol (biologically the most active form of vitamin E). $\alpha$-Tocopherol is the most abundant antioxidant in LDL and many clinical studies aimed at increasing resistance of LDL to oxidation have used supplementation with vitamin E, either singly (6), or in combination with $\beta$-carotene and/or vitamin C (2). The LDL-protective effects were connected mostly with vitamin $\mathrm{E}$. There is a great variation in the ability of LDLs isolated from different donors to resist oxidation, and therefore is not clear whether such response could be a function of the amount of antioxidant present in these samples. A varying correlation exists between the concentration of endogenous $\alpha$-tocopherol in isolated LDLs and their susceptibility to oxidation (6). However, addition of $\alpha$-tocopherol in isolated LDL or ingestion of large doses of vitamin $\mathrm{E}$ increases the lag time for initiation of oxidation (6).

In addition to their LDL-lowering effect, statins may have further beneficial effects on LDL metabolism and LDL composition. We present that pravastatin therapy significantly increased the content of vitamin $\mathrm{E}$ in total cholesterol and non-significantly in dense LDL2 despite decrease of total cholesterol and LDL2 plasma concentration as a lipid carrier. What are the mechanism of such effects is unknown. It may be as a result of the shorter time for which LDL particle circulates. LDL, while circulating, is exposed to time-dependent modifications, such as oxidative stress, depletion of anti-oxidant tocopherols, and nonenzymatic glycation. Agents which stimulate LDL receptor activity are likely to promote the clearance of LDL1 and LDL2, as has been observed (11) and as such shorten the time-dependent consumption of LDL bound vitamin E. There are another possible mechanisms. The $\alpha$-tocopherol content of lipoproteins is determined to a large extent by factors other than the plasma $\alpha$-tocopherol concentration (23). If the rate of LDL precursors clearance under pravastatin therapy increases, secretion of $\alpha$-tocopherol in VLDL from the liver can lead to the enrichment of circulating lipoproteins with $\alpha$-tocopherol (14). As regards LDL subfraction distribution, pravastatin in our study with familial hypercholesterolemic patients decreased the relative concentration of small, dense LDL2, which is believed to be atherogenic. Others were unable to find such effects of pravastatin therapy in the patients with familial combined hyperlipidemia (10). However, increased VLDL and elevated plasma triglyceride levels in combined hyperlipidemia are emerging as the most important determinant of the 
LDL subfraction profile and form pattern-B of LDL profile (LDL2 in excess). Because pravastatin could affect such pathways of lipoprotein metabolism, it is conceivable, but still needs to be proven, that all or some of the above factors may influence the concentration and functional properties of vitamin $\mathrm{E}$ in lipoprotein fractions during hypolipidemic therapy.

We conclude that pravastatin therapy may possess antiatherogenic properties which involve not only its hypocholesterolemic effect, but also its favorable effects on the distribution of LDL subclasses and the content of antioxidant vitamin $\mathrm{E}$ in atherogenic lipoproteins.

Supported in part by grants IGA MH CR No. 2967-3 and GA UK CR, Faculty of Medicine Hradec Králové No. 41351.

\section{References}

1. Aaran RK, Nikkari T. HPLC method for the simultaneous determination of beta-carotene, retinol and alpha-tocopherol in serum. J Pharmacol Biomed Analysis 1988;7:853-7.

2. Abbey M, Nestel PJ, Baghurst PA. Antioxidant vitamins and low density lipoprotein oxidation. Am J Clin Nutr 1993;58:255.

3. Allain CC, Poon LC, Chan CSG, Richmond W, Fu PC. Enzymatic determination of total serum cholesterol. Clin Chem 1974;20:470.

4. Bucolo G, David H. Quantitative determination of serum triglycerides by the use of enzymes. Clin Chem 1973; 19:476.

5. De Leenheer AP, De Bevere VORC, De Ruyter MGM, Clayes AE. Simultaneous determination of retinol and (-tocopherol in human serum by HPLC. J Chromatogr 1979; 162:402-13.

6. Dieber-Rotheneder M, Puhl H, Waeg G et al. Effect of oral supplementation with D-alpha-tocopherol on the vitamin $\mathrm{E}$ content of human low density lipoproteins and resistance to oxidation. J Lipid Res 1991;32:1325-32.

7. Esterbauer H, Rotheneder M, Striegl G et al. Vitamin $\mathrm{E}$ and other lipophilic antioxidants protect LDL against oxidation. Fat Sci Technol 1989;91:316.

8. Esterbauer H, Dieber-Rotheneder M, Waeg G, Striegl G, Jurgens G. Biochemical, structural and functional properties of oxidized low-density lipoprotein. Chem Res Toxicol 1990;3:77-92.

9. Expert Panel on Detection, Evaluation and Treatment of High Blood Cholesterol in Adults. Summary of the second report of the National Cholesterol Education Program (NCEP) Expert Panel on detection, evaluation, and treatment of high blood cholesterol in adults (Adult Treatment Panel II). JAMA 1993;269:3015-23.

10. Franceschini G, Cassinotti M, Vecchio $G$ et al. Pravastatin effectively lowers LDL cholesterol in familial combined hyperlipidemia without changing LDL subclass pattern. Arterioscler Thromb 1994;14:1569-75.

11. Gaw A, Packard CJ, Murray EF et al. Effects of simvastatin on apoB metabolism and LDL subfraction distribution. Arterioscler Thromb 1993;13:170-89.

12. Goldstein JL, Brown MS. The low-density lipoprotein pathway and its relation to atherosclerosis. Ann Rev Biochem 1977;46:897.

13. Hoffman R, Brooks GJ, Aviram M. Hypolipidemic drugs reduce lipoprotein susceptibility to undergo lipid peroxidation: in vitro and ex vivo studies. Atherosclerosis 1992;93:105-13.

14. Kayden HJ, Traber MG. Absorption, lipoprotein transport, and regulation of plasma concentrations of vitamin E in humans. J Lipid Res 1993;34:343-58.

15. Maes M, Weeckx S, Wauters A et al. Biological variability in serum vitamin E concentrations: relations to serum lipids. Clin Chem 1996;42:1824-31.

16. Miller NJ, Paganga G, Wiseman S et al. Total antioxidant activity of low density lipoproteins and the relationship with (-tocopherol status. FEBS Lett 1995;365:164-6.

17. Mitchinson MJ, Ball RY, Carpenter KH, Enright JH, Brabbs CE. Ceroid, macrophages and atherosclerosis. Biochem Soc Transact 1990;18:1066-9.

18. Naito HK. Lipoprotein separations using the TL-100 tabletop ultracentrifuge. Application Note Beckman DS-693.

19. Palinsky W, Rosenfeld ME, Herttuala SY et al. Lowdensity lipoprotein undergoes oxidative modification in vivo. Proc Natl Acad Sci 1989;86:1372-6.

20. Shepherd J. Fibrates and statins in the treatment of hyperlipidemia: in appraisal of their efficacy and safety. Eur Heart J 1995;16:5-13.

21. Steinberg D, Parthasarathy S, Carew TE, Khoo JC, Witztum JL. Beyond cholesterol: Modifications of low density lipoprotein that increase its atherogenecity. N Engl J Med 1989;320:915.

22. Stocker R, Bowry VW, Frei B. Ubiquinol-10 protects human low density lipoprotein more efficiently against lipid peroxidation than does alpha-tocopherol. Proc Natl Acad Sci USA 1991;88:1646.

23. Ziouzenkova O, Winklhofer-Roob BM, Puhl H, Roob JM, Esterbauer H. Lack of correlation between (-tocopherol content of plasma and LDL, but high correlations for (tocopherol and caroteinoids. J Lipid Res 1996;37:1936-46.

Submitted January 1998.

Accepted May 1998.

MUDr. Vladimír Bláha, CSc., Department of Metabolic Care and Gerontology, Charles University, Faculty of Medicine and Teaching Hospital, 50005 Hradec Králové, Czech Republic. 